\title{
Establishing an epidemiosurveillance centre in a resource-constrained setting: A Zambian experience
}

\author{
Raymond Hamoonga* ${ }^{\star 1,2}$, Nadi Songolo ${ }^{1,2}$ and Chimuka Musako² \\ ${ }^{1}$ National Livestock Epidemiological and Information Centre (NALEIC), Lusaka, Zambia; ${ }^{2}$ Department of Veterinary and Livestock \\ Development, Ministry of Agriculture and Livestock, Mansa, Zambia
}

\section{Objective}

This presentation outlines the steps and challenges involved in setting up a regional epidemio-surveillance centre in a resource constrained setting. While this Zambian experience is unique, the challenges encountered are typical of most developing countries and therefore the lessons learned can be applied to much of the developing world.

\section{Introduction}

Livestock diseases in most developing countries are often widely distributed. The wide distribution of diseases often renders whole countries ineligible to participate in international trade of meat and meat products ${ }^{1}$. These trade restrictions serve as a continuous primary source of revenue loss. The World Organisation for Animal Health (OIE) now promotes establishment of disease free zones to lessen the impact of trade restrictions. These "islands" of disease freedom not only serve as a first step in total disease freedom, but for many countries they also serve as a beacon of hope to ever returning to international trade. The selection of a region within a country to be designated as a disease free zone is likely to be based more on the fact that a particular region is yet to experience cases of a given disease than it is on the nation's Veterinary department ability to keep the region disease free. As such, geographical regions that seem to have inherent protection against disease incursions usually due to geospatial features such as mountains, rivers, remoteness etc. serve as the best candidates for creation of disease free zones. Because the process of disease free zone creation is slow, it is important to ensure that disease surveillance is these regions is enhanced so that disease control authorities may serve as agile responders to disease incursions. This current presentation outlines the creation of a Provincial Epidemiological and Information Centre (PEIC) in Zambia's Luapula province. This is only the second epidemiosurveillance centre in the country. Luapula province in the northern part of Zambia being one of only 3 provinces out of a total of 10 provinces that are free of theilleriosis in Zambia ${ }^{2}$ has the potential of being Zambia's largest disease free zone. The challenges as well as lessons learnt from setting up this epidemiosurveillance centre are presented

\section{Methods}

The first task was to create a reliable data management system capable of providing data on disease reports received in the past as well as those that were yet to be received. The second task was to train district staffs in basic epidemiological measures of disease association and measures of health. The recently completed national livestock census provided a basis for establishing base species specific population at risk figures. This enabled the staff to take into account the population at risk when reporting disease occurrence thereby making interpretation of disease incidence reports more meaningful. The third task was to incorporate GIS and spatial epidemiology in disease surveillance. Currently, basic epidemiology formulae are being incorporated into the disease reporting spreadsheets to enable district staff to calculate measures of health and disease association.

\section{Results}

Disease surveillance has now been enhanced in the province. Using Microsoft Excel, a database has been created and is still undergoing improvement. Convention of veterinary camps to GIS point data is underway. District staffs continue to receive training when resources are available. The long term plan is to have these trainings conducted on a regular basis.

\section{Conclusions}

The Luapula province epidemiosurveillance centre was successfully set up. However, challenges continue to be present and are mainly in the form of lack of funding to acquire modern and better data management systems. Similarly, resources to conduct trainings of end users who serve as primary data entry officers are lacking.

\section{Keywords}

Surveillance; Epidemiology; Zambia; Developing country

\section{Acknowledgments}

The authors wish to thank the Zambian National Livestock Epidemiological and Information Centre (NALEIC) directorate and the Ministry of Agriculture and Livestock for availing the data presented here

\section{References}

1. Hamoonga R, Stevenson MA, Allepuz A, Carpenter TE, Sinkala Y. Risk factors for foot-and-mouth disease in Zambia, 1981-2012. Preventive Veterinary Medicine. 2014;114(1):64-71.

2. Makungu C, Mwacalimba KK. A quantitative risk assessment of bovine theileriosis entering Luapula Province from Central Province in Zambia via live cattle imports from traditional and commercial production sectors. Preventive Veterinary Medicine. 2014;116(12):63-74.

\footnotetext{
*Raymond Hamoonga

E-mail: geminivet@gmail.com
} 